\title{
COMPARATIVE MORPHOLOGICAL STUDIES OF TRANSPLANT SARRACENIA PURPUREA L. (SARRACENIACEAE) POPULATIONS IN Maryland, West Virginia, and Pennsylvania
}

\begin{abstract}
Adam Hnatkovich - West Virginia University - Department of Biology • Life Sciences Building • Morgantown, West Virginia 26505•USA・ahnatkov@mix.wvu.edu

HoNGQI LI • Frostburg State University • Department of Biology • 101 Braddock Road • Frostburg, Maryland 21532•USA・hli@frostburg.edu
\end{abstract}

Keywords: Sarracenia purpurea, morphology, population, Allegheny, carnivorous

\section{Abstract}

At least eight populations of Sarracenia purpurea in western Maryland, West Virginia, and southwestern Pennsylvania were transplanted from Glade Run Bog, Pennsylvania in the 1940s, but their current status had been unknown. We have conducted population and morphological analyses of six of these transplant populations. Our results revealed significant variation in flower and pitcher morphology among populations. Morphological variation could be correlated with the physical and chemical environment that each population inhabits. Future research may reveal if morphological variation that is expressing among transplanted populations could be caused by environmental factors.

\section{Introduction}

Sarracenia purpurea is found throughout Canada and the eastern United States from Maine to Georgia (Schnell 1979, 2002). However, native populations of S. purpurea are continuously decreasing within the Allegheny highlands of Maryland, West Virginia, and Pennsylvania. The last native population of S. purpurea was found at Glade Run Bog, Pennsylvania, by Schrock in 1939. Unfortunately, Glade Run Bog was destroyed during the construction of High Point Lake (Somerset County, Pennsylvania) in the 1940s. Prior to the lake's construction, a number of $S$. purpurea individuals were transplanted into (at least) eight wetlands within the Allegheny Mountain region: Spruce Flats Bog (SFB) and Mount Davis Bog (MDB) in southwestern Pennsylvania, Rock Lodge Wetland (RLW) and Cunningham Swamp (CHS) in western Maryland, and Cranesville Swamp (CVS), Big Run Bog (BRB), Cranberry Glades (CRG), and Helmick Run Swamp in West Virginia (MacKenzie, pers. comm.). Prior to our investigation (see Hnatkovich 2007), the current population status and morphological profile of these transplant populations had not been quantified. It was necessary to investigate population size and morphological variation among populations to identify regionally unique and/or threatened ecotypes that may warrant further investigation and conservation. We hypothesized that after more than 60 years of geographical isolation, the transplant populations could vary significantly in terms of pitcher morphology and flower morphology.

Morphology of pitcher plant leaves (pitchers) is thought to be affected by certain environmental factors, such as pore-water nutrient availability (Ellison \& Gotelli 2002; Ellison et al. 2004). Furthermore, the color, size, and shape of pitchers could be related to insect attraction (Newell \& Nastase 1998). In our study, transplanted Sarracenia purpurea populations have originated from a single "source" population: this provides us with an unusual opportunity to comparatively study plant morphology in different wetland environments after an extended period of isolation. Populations were transplanted into wetlands that are dominated by different vegetative communities, and wetlands are located across a range of elevations and latitudes. Therefore, transplant locations could also be highly variable in terms of hydrologic cycles and/or availability of micro- and macronutrients. Most importantly, variation in environmental conditions among transplant locations could be associated with 
variation in S. purpurea morphology and historical reproductive success. We have investigated six of the eight transplant $S$. purpurea populations, and detected significant differences among populations in regard to pitcher and flower morphology. Our estimates of population size suggest that each population could have experienced different historical reproductive success. In the future, it will be essential to identify environmental variables that affect $S$. purpurea population size, population and individual growth rates, and morphology in these transplant populations. By understanding the relationship between $S$. purpurea and its environment, it may be possible to develop more appropriate conservation strategies for regional S. purpurea populations within the Alleghenies.

\section{Methods}

Geographical characteristics of the six S. purpurea populations (SFB, MDB, BRB, RLW, CVS, CRG, Table 1) are based on Hnatkovich's thesis (2007). Data collection was conducted during late summer and early fall in 2006 (from September 15 to October 6). At each population, flower morphological data were collected from 20, randomly selected, flowering individuals (see Figure 1). For plants that had more than one flower, data were also collected from (up to) two additional flowers. From the smallest population at Cranesville Swamp, all flowering plants (14 individuals) were sampled. Flower data included calyx diameter, stigma umbel diameter, and pistil height (from receptacle to the stigma top). Mean calyx diameter, umbel diameter, and pistil height were calculated for each population (see Figure 1). It should be noted that flower morphological characters did not vary significantly within each population. Pitcher morphological data of the most fully developed, first-year pitchers were collected from 50 randomly selected individuals (see Figure 2). We calculated and compared the metrics relative mouth area, keel width, hood size, hood height, and hood area. Methods of calculating these metrics are discussed elsewhere (Hnatkovich 2007). These data may represent differences in pitcher-shape better than absolute measurements, and also could reflect the degree of expression of carnivorous structures (Ellison \& Gotelli 2002; Ellison et al. 2004) among transplant populations.

Prior to statistically analyzing data, tests for normality of residuals, using the Kolmogorov-Smirnov, Anderson-Darling, Shapiro-Wilk, and Cramer-von Mises tests, were performed in SAS (SAS Institute, ver. 8.9). Levene's Tests for equal variances (not assuming a normal distribution) for each metric were performed in Minitab (ver. 13.2). Flower and pitcher morphological data were compared among populations using a One-Way ANOVA $(\alpha=0.05$; SAS, ver. 8.9). Multiple comparison tests were performed in SAS (ver. 8.9; $\alpha=0.05$ ) using Tukey's Studentized Range (HSD). Lastly, a Spearman's correlation test was performed in SAS (SAS Institute, ver. 8.9) to examine the relationship between relative keel width and relative mouth area metrics $(\mathrm{p}=0.05)$, and among all relative metrics (Bonferoni adjusted; $\mathrm{p}=0.005$ ).

It should be noted that the metrics relative mouth area and relative keel width were derived (and in some cases adapted) from the work of Ellison et al. (2004; length: mouth diameter ratio) and Ellison \& Gotelli (2002; relative keel size and relative tube diameter). However, these metrics may not be identical to those of Ellison \& Gotelli (2002) and Ellison et al. (2004): mouth area, rather than mouth diameter, was used to calculate a metric to describe the relationship between the size of the pitcher opening and the length of the pitcher. Similarly, the locations on pitcher leaves from which we collected data to calculate our metric "relative keel width" may have deviated from those locations used by Ellison \& Gotelli (2002) and Ellison et al. (2004): our keel-metrics may not represent the same relationships as the keel-metrics of other authors.

\section{Results}

Geographical characteristics of the six study wetlands (SFB, MDB, BRB, RLW, CVS, CRG) are provided in Table 1. Significant differences in the size of calyx diameters, stigma diameters, and pistil length were detected among populations $(\mathrm{p}<0.0001)$. Sarracenia purpurea populations at Rock Lodge Wetland and Cranesville Swamp displayed the largest flowers. These populations' calyx diameters, stigma diameters, and pistil heights were significantly larger than all other populations, but were not 
significantly different from each other within each population (see Figure 1). Significant differences among populations were consistent across all flower morphological characters. Cranesville Swamp and Rock Lodge Wetland displayed the largest flowers, while the remaining populations were ranked (largest to smallest) as follows: Mount Davis, Cranberry Glades, Big Run Bog, and Spruce Flats Bog (see Figure 1).

Comparisons of relative metrics of pitcher morphology revealed significant differences in the expression of carnivory $(\mathrm{p}<0.0001)$ and hood morphology $(\mathrm{p}<0.0001)$. Cranesville and Rock Lodge populations are not different when comparing all relative pitcher metrics, and displayed the largest relative mouth areas (largest expression of carnivory) of all populations (see Figure 2). Also, Spruce Flats Bog displayed the smallest relative mouth area, and the second largest relative keel widths (least expression of carnivory). Spearman's correlation test revealed a significant negative correlation between relative keel width and relative tube diameter $(\mathrm{p}<0.0001)$. Also, there was a significant negative correlation between relative hood-surface area and relative keel size $(\mathrm{p}<0.0001)$, and a significant positive correlation between relative hood-surface area and relative tube diameter $(\mathrm{p}<0.0001)$.

\section{Discussion}

Significant differences in pitcher morphology among populations could represent the phenotypic plasticity of Sarracenia purpurea, rather than genetic divergence (Ellison \& Gotelli 2002). A significant negative relationship between relative mouth area and relative keel width, as revealed by Spearman's correlation test, suggests that carnivorous structures are reduced as the non-carnivorous keel increases in width (see also Ellison \& Gotelli 2002). The biological significance of variation in hood size and shape remains in question, as this form of morphological variation is not often discussed in the literature, and is probably a phenotypically plastic trait. From the above data, there are significant differences among populations in terms of relative hood size and area (see Figure 2), and considerable variation in approximate hood-surface area among populations (Hnatkovich 2007). There was a significant negative correlation between relative hood-surface area and keel size, and a positive correlation between hoodsurface area and tube diameter. These data suggest that hood area is related to carnivory, and that hood area should increase as $S$. purpurea relies more heavily on carnivory.

According to Ellison \& Gotelli (2002), the negative correlation between the relative keel width and relative tube diameter could be the result of the availability of certain nutrients. More specifically, increasing available nitrogen in soil could lead to increase in keel width and a decrease in the diameter of the pitcher-opening (Ellison \& Gotelli 2002). In future studies of these transplant populations, the amount of available nitrogen and other limiting nutrients at these populations should be analyzed in the context of pitcher morphology. Determining the response of these transplant populations to $\mathrm{N}$-availability may be of great importance in the Allegheny Mountains: according to Peterjohn et al. (1996), Pennsylvania, Maryland, and West Virginia have experienced some of the largest depositions of nitrogen in the eastern United States.

It may be possible that annual temperature regimes associated with elevation and latitude may affect each S. purpurea population's growing season length, rate of pitcher development, and the subsequent expression of morphological characteristics. Populations at higher elevations and higher latitudes experience lower annual temperature, which could result in a shorter growing season. Although we did not directly measure seasonal temperature variation among populations, we have noticed that new pitchers and flower buds emerged at different dates among these populations: new pitchers and flower buds emerged approximately two weeks earlier at Cranesville and Rock Lodge populations (during the summer of 2006) than at any other population. Surface-substrate, soil properties, parent-material, frost damage (Chapin \& Pastor 1995), severity of winter, and lifting of a winter-formed ice-sheet during spring thaw (pers. obser.) may all be important governing factors of pitcher morphology during the growing season. 
Cranesville Swamp and Rock Lodge Wetland populations displayed the largest flowers of all transplant populations (see Figure 1). We have not encountered any published literature that report variation in flowers in S. purpurea populations in the context of environmental variables (i.e. nutrient availability). While we cannot infer (with any certainty) that differences in environmental variables among wetlands are responsible for differences in flower size, we do not disregard this possibility. We have experimentally transplanted several $S$. purpurea individuals from Mount Davis Bog to Frostburg State University's greenhouse, and also to a controlled, outdoor location. However, flowers of these plants have not become noticeably larger after two years ( $\mathrm{Li}$, unpub. data).

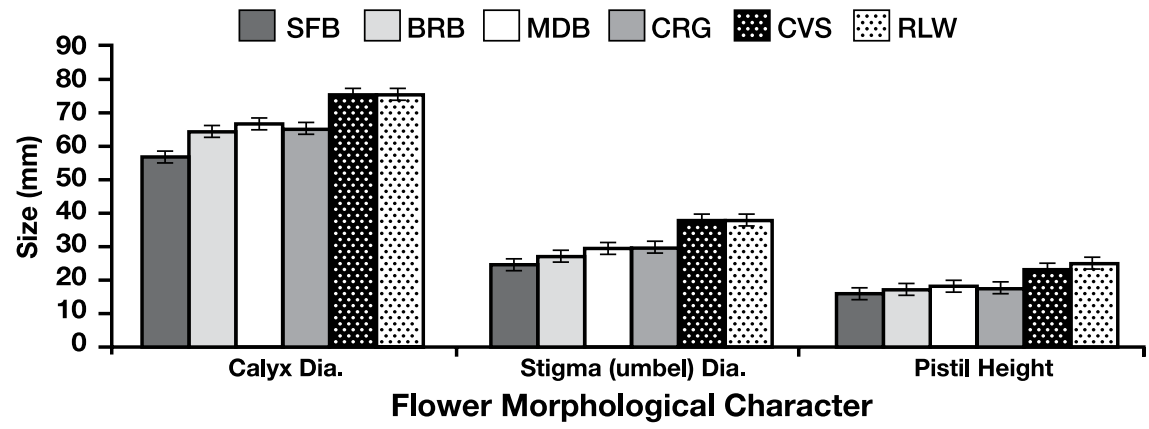

Figure 1: Mean calyx diameter $(\mathrm{mm})$, mean stigma diameter $(\mathrm{mm})$, and mean pistil height $(\mathrm{mm})$ of Sarracenia purpurea, with standard error bars.

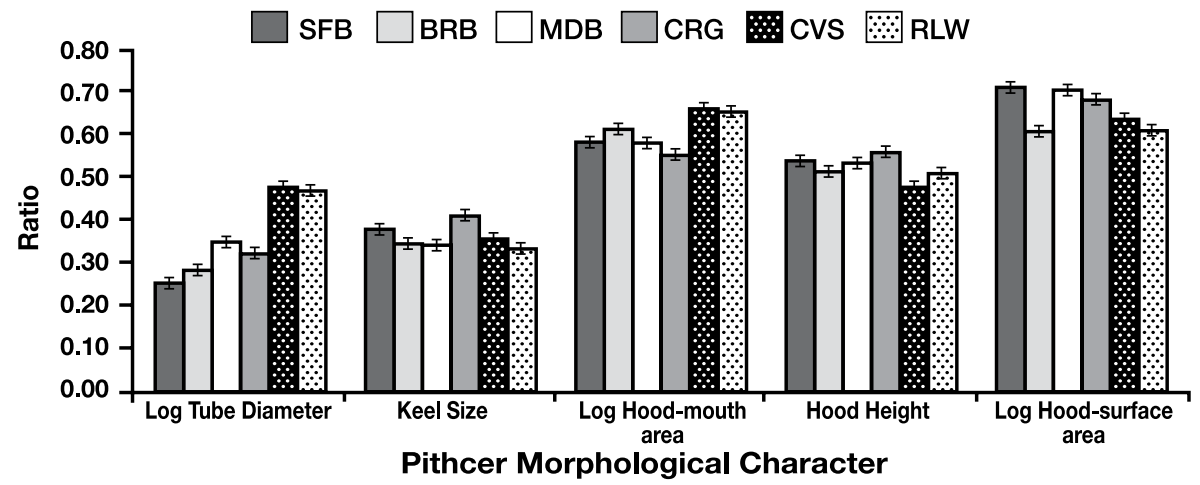

Figure 2: Mean relative metrics of Sarracenia purpurea with standard error bars.

It is also possible that differences among transplant populations' flower morphology are representative of genetic differences among populations. However, it is difficult to infer this relationship without genetic information from our transplant populations and the historical founders of each population (representative of Glade Run Bog). Because the $S$. purpurea population at Glade Run Bog was isolated for an unknown number of generations (thought to be the last native population in the region; Mackenzie, pers. comm.) prior to the transplant-events, it is possible that genetic variation had been drastically reduced as a result of genetic drift or other evolutionary mechanisms. Additional historical data has been provided by the Westmoreland County Botanical Society (pers. comm.) regarding the transplant event at Spruce Flats Bog. These historical data suggest that the number of founding individuals at Spruce Flats was less than 20. As of 2006, the estimated population size of $S$. purpurea at Spruce Flats Bog was approximately 157,000 adults (flowering and non-flowering) and 213,000 seedlings (Hnatkovich 2007). Additionally, all transplant events were conducted by the same individuals (MacKenzie, pers. comm.; see also Hnatkovich 2007). Because of the extremely small $S$. purpurea population sizes at Cranesville Swamp (32 plants), and Cunningham Swamp (approx. 200 
adult plants), we suggest that all transplant populations could have developed from a small number of initial individuals (Hnatkovich 2007): this could have resulted in a founder effect at each population, leading to reduced genetic variation in contemporary populations. After 60 years, with hypothesized differences in population growth rates among populations (Hnatkovich 2007), we may expect these populations to be genetically dissimilar as a result of reproductive isolation.

Table 1: Summary of Sarracenia purpurea population characteristics.

\begin{tabular}{ccccc}
\hline Location & $\begin{array}{c}\text { Approximate } \\
\text { Elevation (m) }\end{array}$ & $\begin{array}{c}\text { Latitude } \\
\text { (UTM, NAD27) }\end{array}$ & $\begin{array}{c}\text { Approximate land- } \\
\text { area occupied by } \\
\text { S. purpurea } \\
\text { (ha) }\end{array}$ & $\begin{array}{c}\text { Estimated } \\
\text { population size }\end{array}$ \\
\hline \hline CRG & 1028.7 & 563652 & 0.25 & 130 (census) \\
& 829.1 & 655565 & & 287,544 \\
SFB & & $\begin{array}{c}\text { (NAD83) } \\
655327\end{array}$ & 2.5 & 17,000 \\
MDB & 979.3 & 622565 & 0.75 & 327,217 \\
BRB & 979.9 & 645640 & 2 & 1441 (census) \\
RLW & 804.7 & 630383 & 0.25 & 32 (census) \\
CVS & 780.3 & 645640 & 0.25 & 200 \\
CHS & 780.3 & & 1 & \\
\hline
\end{tabular}

Update: In 2009, the land manager decided that the transplanted pitcher plants were not natural in Cranesville Swamp and dug them out completely.

Acknowledgements: Authors are grateful to Dr. Martin MacKenzie (USDA Forest Service) for his immeasurable assistance in field and for historical data concerning all populations. We also thank Dr. Frank Ammer (Department of Biology, FSU) and Dr. Fred Senese (Department of Chemistry, FSU) for their contributions to our experimental design. This research was originally submitted in fulfillment of the degree of Master of Science, Department of Biology, Frostburg State University, Frostburg, MD (2007). This paper was originally presented at the 6th Conference of the International Carnivorous Plant Society, June 1-5, 2006, Frostburg, Maryland, USA.

\section{References}

Chapin, C.T., and Pastor, J. 1995. Nutrient limitations in the northern pitcher plant Sarracenia purpurea. Can. J. Bot. 73: 728-734.

Ellison, A.M., and Gotelli, N.J. 2002. Nitrogen availability alters the expression of carnivory in the northern pitcher plant. Proc. Nat. Acad. Sci. 99: 4409-4412.

Ellison, A.M., Buckley, H.L., Miller, T.E., and Gotelli, N.J. 2004. Morphological variation in Sarracenia purpurea (Sarraceniaceae): geographic, environmental, and taxonomic correlates. Amer. Jour. Bot. 91: 1930-1935.

Hnatkovich, A. 2007. A Comprehensive Study of Transplant Populations of Sarracenia purpurea in Western Maryland, Southwestern Pennsylvania, and West Virginia, USA. Masters Thesis. Department of Biology, Frostburg State University. Frostburg, Maryland.

Minitab Incorporated. 2000. Version 13.2. Minitab Incorporated, State College, Pennsylvania.

Newell, S.J., and Nastase, A.J. 1998. Efficiency of insect capture by Sarracenia purpurea (Sarraceniaceae), the northern pitcher plant. Amer. J. Bot. 85: 88-91.

Peterjohn, W.J., Adams, M.B., and Gilliam, F.S. 1996. Symptoms of nitrogen saturation in two central Appalachian hardwood forest ecosystems. Biogeochem. 35: 507-522.

SAS Institute. 2003. Version 8.9. SAS Institute, Cary, North Carolina.

Schnell, D.E. 1979. A critical review of published variants of Sarracenia purpurea L. Castanea 44: 47-59. Schnell, D.E. 2002. Carnivorous Plants of the United States and Canada. 2nd edition. Timber Press, Portland, Oregon.

Schrock, A.E. 1939. A Comparative Study of the Development and Composition of Two Bogs in Eastern United States. Masters Thesis. Kent State University, Kent, Ohio. 